\title{
Stability Analysis of Discretized Structure Systems Based on the Complex Network with Dynamics of Time-varying Stiffness
}

\author{
Chaoyu Wang ${ }^{1}$ and Yinhe Wang ${ }^{2}$ \\ ${ }^{1}$ CCTEG Chongqing Engineering Co., Ltd, Chongqing, P. R. China \\ ${ }^{2}$ Guangdong University of Technology
}

October 12, 2020

\begin{abstract}
The stability analysis of dynamic continuous structural system (DCSS) has often been investigated by discretizing it into several low-dimensional elements. The integrated results of all elements are employed to describe the whole dynamic behavior of DCSS. In this paper, DCSS is regarded as the complex dynamic network with the discretized elements as the dynamic nodes and the time-varying stiffness as the dynamic link relations between them, by which the DCSS can be regarded to be the large-scale system composed of the node subsystem (NS) and link subsystem (LS). Therefore, the dynamic model of DCSS is proposed as the combination of dynamic equations of NS and LS, in which their state variables are coupled mutually. By using the model, this paper investigates the stability of DCSS. The research results show that the state variables of NS and LS are uniformly ultimately bounded (UUB) associated with the synthesized coupling terms in LS. Finally, the simulation example is utilized to demonstrate the validity of method in this paper.
\end{abstract}

\section{Hosted file}

Cover Letter.pdf available at https://authorea.com/users/366458/articles/486215-stabilityanalysis-of-discretized-structure-systems-based-on-the-complex-network-with-dynamics-oftime-varying-stiffness

\section{Hosted file}

Highlights.pdf available at https://authorea.com/users/366458/articles/486215-stabilityanalysis-of-discretized-structure-systems-based-on-the-complex-network-with-dynamics-oftime-varying-stiffness

\section{Hosted file}

Manuscript-For Review.pdf available at https://authorea.com/users/366458/articles/486215stability-analysis-of-discretized-structure-systems-based-on-the-complex-network-withdynamics-of-time-varying-stiffness 

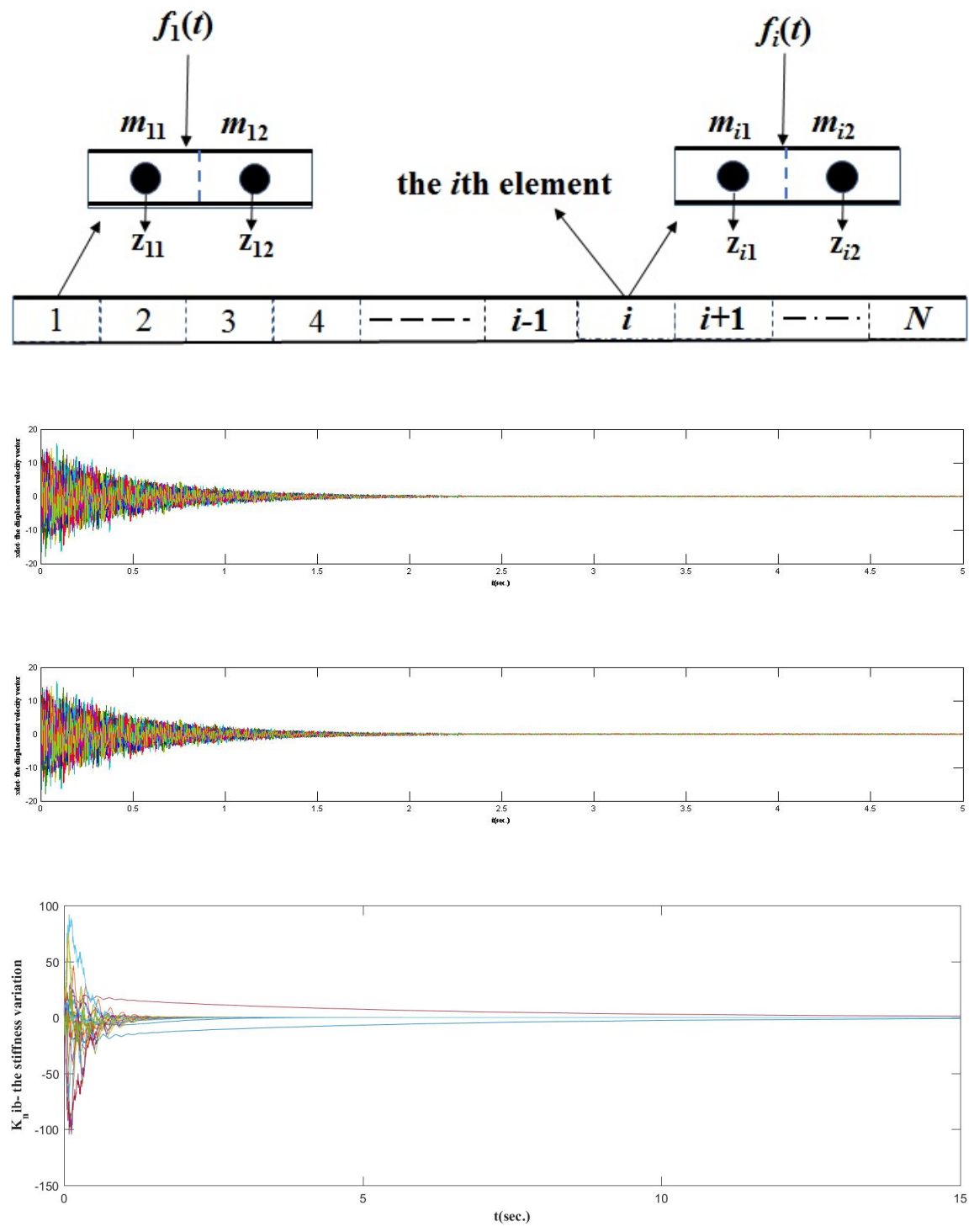

2 